\title{
The Magneto-Natural Convection Flow of a Micropolar Hybrid Nanofluid over a Vertical Plate Saturated in a Porous Medium
}

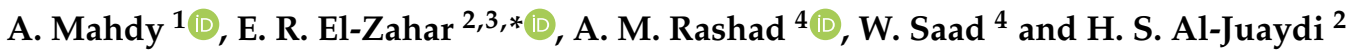 \\ 1 Department of Mathematics, Faculty of Science, South Valley University, Qena 83523, Egypt; \\ mahdy4@yahoo.com \\ 2 Department of Mathematics, College of Science and Humanities in Al-Kharj, Prince Sattam bin Abdulaziz \\ University, Al-Kharj 11942, Saudi Arabia; H.S.Aljuaydi@gmail.com \\ 3 Department of Basic Engineering Science, Faculty of Engineering, Menoufia University, \\ Shebin El-Kom 32511, Egypt \\ 4 Department of Mathematics, Faculty of Science, Aswan University, Sahary 81528, Egypt; \\ am_rashad@yahoo.com (A.M.R.); wafaamath664@gmail.com (W.S.) \\ * Correspondence: er.elzahar@psau.edu.sa
}

Citation: Mahdy, A.; El-Zahar, E.R.; Rashad, A.M.; Saad, W.; Al-Juaydi, H.S. The Magneto-Natural Convection Flow of a Micropolar Hybrid Nanofluid over a Vertical Plate Saturated in a Porous Medium. Fluids 2021, 6, 202. https://doi.org/ $10.3390 /$ fluids 6060202

Academic Editor: Igor

V. Miroshnichenko

Received: 16 April 2021

Accepted: 25 May 2021

Published: 27 May 2021

Publisher's Note: MDPI stays neutral with regard to jurisdictional claims in published maps and institutional affiliations.

Copyright: (c) 2021 by the authors. Licensee MDPI, Basel, Switzerland. This article is an open access article distributed under the terms and conditions of the Creative Commons Attribution (CC BY) license (https:// creativecommons.org/licenses/by/ $4.0 /)$.

\begin{abstract}
In this study, we investigate the convective flow of a micropolar hybrid nanofluid through a vertical radiating permeable plate in a saturated porous medium. The impact of the presence or absence of the internal heat generation (IHG) in the medium is examined as well as the impacts of the magnetic field and thermal radiation. We apply similarity transformations to the non-dimensionalized equations and render them as a system of non-linear ODEs (Ordinary Differential Equations) subject to appropriate boundary conditions. This system of non-linear ODEs is solved by an adaptive mesh transformation Chebyshev differential quadrature method. The influence of the governing parameters on the temperature, microrotation and velocity is examined. The skin friction coefficient and the Nusselt number are tabulated. We determine that the skin friction coefficient and heat transport rate increase with the increment in the magnetic field. Moreover, the increment in the micropolarity and nanoparticle volume fraction enhances the skin friction coefficient and the Nusselt number. We also conclude that the IHG term improved the flow of the hybrid nanofluid. Finally, our results indicate that employing a hybrid nanofluid increases the heat transfer compared with that in pure water and a nanofluid.
\end{abstract}

Keywords: natural convection; micropolar; MHD; hybrid nanofluid; internal heat generation

\section{Introduction}

The phenomenon of the natural convection process in porous media has become one of the most interesting studies in the last two centuries. This interest is due to its major application in several industries such as filtration operations, thermal insulation, oceanography, geothermal systems, building insulation, geothermal tanks, geophysics, nuclear flow, metallurgy, cooling of electronic tools and separation operations in chemical industries, for example. Excellent reviews of these applications, the governing equations and different statuses of this topic may be found in the monographs presented by Nield and Bejan [1], Ingham and Pop [2] and Vafai [3]. Moreover, the study of nanoparticles has attained a massive importance because of its applications in the field of biological science and technological industries such as biomedical sciences, industrial cooling, nanodrug delivery, solar absorption, electromechanical systems and much more. The expression 'nanofluid' was devised by Choi [4], which indicates engineering colloids that consist of nanoparticles scattered in a regular liquid for improving thermal conductivity. Nanofluid is normally utilized to enhance the heat transport rate of the regular fluid. It is a mixed nanosized particle $(1-100 \mathrm{~nm})$ that is suspended inside the base fluid. Nanofluid is normally yielded of metals, oxides, carbides and nanometals. The pure liquid is prevalent in blood, 
water, ethylene glycol and so on. Eastman et al. [5] carried out research that observed that thermal conductivity was improved when copper nanoparticles were added up into the regular liquid (water). Furthermore, they discovered that the thermal conductivity was enhanced by enlarging the copper nanoparticles into the basic liquid. Buongiorno [6] discussed in his investigation that there were several techniques that were important to boost the thermal conductivity of the basic liquid. Several research studies on the flow of nanoliquids have been analyzed in the pertinent literature; see [7-11].

MHD (magnetohydrodynamics) nanofluid has a great use in the field such as optic stimulators, magneto-optical fabric wavelength sensors, floating isolation, pharmacology, optical fibers, non-linear optical devices, hypoxia and so on. The magneto-nanofluid has the features of both liquids and magnets. The magnetic strength creates the rebuild of the concentration and dissolved particles within the liquid regime that greatly impacts the flow simulation of the heat transference. The concept Magneto-nanofluid flow is effective in driving the particles while the tissues up the flow of the blood due to the reality that the magnetic nanoparticles are more viscous to tissue cells than the nonmalignant cell forms. These particles spend more energy than the microparticulates in opposing current magnetic intensities probable in humans such as in cancer medication. Rashad [12] investigated the magneto-nanofluid flow on a radiative wedge. Sandeep et al. [13] explored magneto-nanoparticles by representing a fully accurate numerical simulation. Dogonchi et al. [14] scrutinized the magneto-natural convection of nanofluid in a horizontal semi-cylinder. EL-Zahar et al. [15] investigated the effect of the sinusoidal surface temperature on the free convective flow of MHD nanofluid along a vertical plate. Nabwey et al. [16] analyzed the unsteady slip flow of MHD nanofluid through a radiative stretchable surface with convective heating. However, in the resumption of nanofluid investigation, authors have lately attempted to use a hybrid nanofluid, which is engineered by suspending several nanoparticles either in a mixture or a composite shape. Additionally, to achieve a desired and large thermal conductivity, applying a hybrid nanofluid can lead to a final cost reduction and the appropriate stability of nanofluid in addition to supplying the groundwork of the tremendous manufacturing. The concept of employing a hybrid nanofluid is to furthermore boost the heat transference and pressure descend features by the trade-off between the disadvantages and the characteristics of the individual suspension assigned to a perfect portion rate, the synergistic effect of nanomaterials and a better thermal network (see [17-20]).

On the other side, many investigators have analyzed non-Newtonian fluids in several aspects because they have a further usage in different industrial processes. Such kinds of fluids are especially utilized in the production of permeable pipes, coated sheets, plastic polymers, visual fibers and filters, for example. These types of fluids cannot be explored by a single constitutive pattern with the aspect of their divergent attributes and they can be classified into integral, differential and rate kinds. Away from these kinds, differential type fluids have been performed by various researchers because they have several applications in the industrial process. One of the easiest subclasses of the differential fluid category is micropolar fluid. Micropolar fluids can be employed to debate the rendering of impure oils, lubricants, suspension of polymers and crystals of fluids; see Eringen [21]. Ariman et al. [22] investigated the special characteristics of micropolar fluids comprehensively. Ahuja [23] estimated in his experimental study that the improvement in heat transference may be due to the rotation of nanoparticles about their center due to the shear stress influence and hence a three-dimensional hydrodynamic boundary layer was also observed. The rotating micro-constituents' influence in nanofluid should be classified to perceive the fluid flow behavior in a favored mode and therefore the micropolar notion elucidates the variation between computational and experimental notices. However, a novel type of nanofluid as a micropolar fluid has been elucidated by several authors. Bourantas and Loukopoulos [24] examined the MHD free convection flow of micropolar nanofluid driven inside an enclosure. Bourantas and Loukopoulos [25] explored the natural convection flow of micropolar nanoliquids. They discovered that the microrotations in general reduced the overall heat 
transference from the heated side and should not be removed. Rashad et al. [26] interpreted the combined convection flow of micropolar nanofluid past a horizontal cylinder in a porous medium. Rashad et al. [27] also analyzed the unsteady slip flow of a micropolar nanofluid over a vertical stretchable surface. They found out that the skin friction decreased expressively along the stretchable surface for both metallic and non-metallic nanoparticles and also it reduced with the volume fraction parameter. Other recent reports performed by researchers relevant to this topic can be found in [28-32].

Based on the above-mentioned benefits of a hybrid nanofluid, it is expected that an advanced nanofluid has a significant role in the future of nanofluid science and researchers have shown a greater tendency toward the investigation of a hybrid nanofluid and the impact of these fluids on heat transfer and pressure drop characteristics. However, the insistence of the current research is to derive a theoretical inspection of the magnetonatural flow of a micropolar hybrid nanofluid across a vertical radiative permeable plate drenched in a porous medium in the existence of internal heat generation. An adaptive mesh transformation Chebyshev differential quadrature method (ACDQM) is applied to obtain accurate numerical results for the velocity, temperature and angular velocity profiles. The impacts of the interesting parameters on the flow are debated graphically. The arithmetical model is determined for the present survey and resolved computationally after employing the proper transmutations. The effectiveness of various relevant parameters on the momentum and thermal distributions along with drag friction and transfer heat are inspected with the aid of plot explanations and tabular forms.

\section{Problem Formulation}

Consider the investigation of the magneto-natural convective flow of a hybrid nanofluid past an orthogonal permeable plate in a saturated porous medium. The influence of external thermal radiation is addressed to enhance the thermal properties of the hybrid nanoliquid. The conducting medium is also considered by a uniform magnetic field. The configuration of the flow and coordinate system is exhibited in Figure 1. Let us consider that $\mathrm{x}$ be the distance of the plate and $\mathrm{y}$ the normal distance of the plate. $T_{w}$ is the plate temperature, $N$ is the angular velocity, $k$ is the viscosity of the vortex, $g^{*}$ is the gravity, $q^{\prime \prime \prime}$ is the IHG of the fluid, $B_{0}$ is the magnetic field strength, $K$ is the permeability of the porous medium, $\gamma$ the viscosity of the spin gradient and $j$ is the density of micro-inertia.

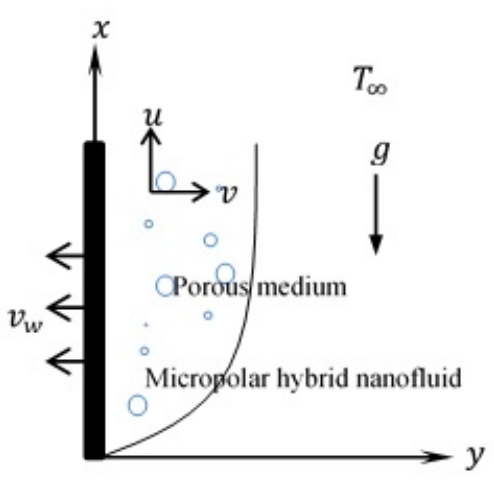

Figure 1. Configuration of the flow.

The flow is presumed to be laminar and the micropolar hybrid nanofluid is given to be incompressible and electrically conducting with uniform properties and a thermal equilibrium between the water-based micropolar hybrid nanofluid containing two types of nanoparticles: copper $(\mathrm{Cu})$ and non-metallic nanoparticles, alumina $\left(\mathrm{Al}_{2} \mathrm{O}_{3}\right)$. The thermophysical properties of the water and nanofluid are listed in Table 1. By taking into consideration the boundary layer and Boussinesq approximations, the governing equations of this system are given as follows (see [33]): 
Table 1. Thermophysical properties of water, copper and alumina [30,31].

\begin{tabular}{cccc}
\hline $\begin{array}{c}\text { Thermophysical } \\
\text { Properties }\end{array}$ & $\mathbf{H}_{\mathbf{2}} \mathbf{O}$ & $\mathbf{A l}_{\mathbf{2}} \mathbf{O}_{\mathbf{3}}$ & $\mathbf{C u}$ \\
\hline$\rho$ & 997.1 & 3970 & 8954 \\
$C_{p}$ & 4179 & 765 & 383 \\
$k$ & 0.613 & 40 & 400 \\
$\beta \times 10^{5}$ & 21 & 0.85 & 1.67 \\
$\sigma$ & 0.05 & $1 \times 10^{-10}$ & $5.96 \times 10^{7}$ \\
\hline
\end{tabular}

Continuity equation:

$$
\frac{\partial u}{\partial x}+\frac{\partial v}{\partial y}=0
$$

Momentum equation:

$$
\begin{aligned}
& u \frac{\partial u}{\partial x}+v \frac{\partial u}{\partial y}=\frac{\mu_{h n f}+k}{\rho_{h n f}}\left(\frac{\partial^{2} u}{\partial y^{2}}\right)+\frac{g^{*}(\rho \beta)_{h n f}\left(T-T_{\infty}\right)}{\rho_{h n f}}-\frac{\sigma_{h n f} B_{0}^{2}}{\rho_{h n f}} u+\frac{k}{\rho_{h n f}} \frac{\partial N}{\partial y}-\frac{\mu_{h n f}+k}{\rho_{h n f}}\left(\frac{u}{K}\right) . \\
& \text { Energy equation: } \\
& u \frac{\partial T}{\partial x}+v \frac{\partial T}{\partial y}=\frac{1}{\left(\rho C_{p}\right)_{h n f}}\left[k_{h n f} \frac{\partial^{2} T}{\partial y^{2}}-\frac{\partial q_{r}}{\partial y}+q^{\prime \prime \prime}\right] . \\
& u \frac{\partial N}{\partial x}+v \frac{\partial N}{\partial y}=\frac{\gamma_{h n f}}{j \rho_{h n f}} \frac{\partial^{2} N}{\partial y^{2}}-\frac{k}{j \rho_{h n f}}\left(2 N+\frac{\partial u}{\partial y}\right) . \\
& \left.\begin{array}{c}
\text { at } y=0: u=0, v=v_{w}, T=T_{w}(x)=T_{\infty}+C x^{\lambda}, N=-n \frac{\partial u}{\partial y} \\
u=0, T=T_{\infty}, N=0 \text { as } y \rightarrow \infty
\end{array}\right\} . \\
& \psi(x, y)=4 v_{f}\left(\frac{G r_{x}}{4}\right)^{\frac{1}{4}} f(\eta), \eta=\left(\frac{G r_{x}}{4}\right)^{\frac{1}{4}} \frac{y}{x}, N(x, y)=4 \frac{v_{f}}{x^{2}}\left(\frac{G r_{x}}{4}\right)^{\frac{3}{4}} g(\eta), \\
& G r_{x}=\frac{g^{*} \beta_{f}\left(T_{w}-T_{\infty}\right) x^{3}}{v_{f}^{2}}, u=\psi_{y}=\frac{4 v_{f}}{x}\left(\frac{G r_{x}}{4}\right)^{\frac{1}{2}} f^{\prime}=U f^{\prime} \\
& v=-\psi_{x}=-\frac{(\lambda+3) v_{f}}{x}\left(\frac{G r_{x}}{4}\right)^{\frac{1}{4}} f+(1-\lambda) v_{f}\left(\frac{y}{x^{2}}\right)\left(\frac{G r_{x}}{4}\right)^{\frac{1}{2}} f^{\prime}, q^{\prime \prime \prime}=\frac{k_{h n f}\left(T_{w}-T_{\infty}\right)}{x^{2}}\left(\frac{G r_{x}}{4}\right)^{\frac{1}{2}} e^{-\eta}
\end{aligned}
$$

where $u$ is the velocity in $x$ direction, $v$ is the velocity in $y$ direction, $\psi(x, y)$ is the stream function, $\eta$ is the similarity variable and $G r_{x}$ is the Grashof number.

Let us present the following terms of a hybrid nanofluid. $\rho_{\text {hnf }}$ is the nanofluid density, which is the nanofluid as specified by Ho et al. [37], $\mu_{h n f}$ is the effective dynamic viscosity, 
$c_{\text {phnf }}$ is the heat capacity according to Ho et al. [38], $\beta_{h n f}$ is the expansion of the thermal, $K_{h n f}$ is thermal conductivity and $\sigma_{\text {hnf }}$ is the coefficient conductivity for electricity.

$$
\begin{gathered}
\rho_{h n f}=\phi_{1} \rho_{1}+\phi_{2} \rho_{2}+(1-\phi) \rho_{f} \\
\mu_{h n f}=\mu_{f}\left(1-\left(\phi_{1}+\phi_{2}\right)\right)^{2.5} \\
\left(\rho c_{p}\right)_{h n f}=\phi_{1}\left(\rho c_{p}\right)_{1}+\phi_{2}\left(\rho c_{p}\right)_{2}+(1-\phi)\left(\rho c_{p}\right)_{f} \\
(\rho \beta)_{h n f}=\phi_{1}(\rho \beta)_{1}+\phi_{2}(\rho \beta)_{2}+(1-\phi)(\rho \beta)_{f} \\
\frac{k_{h n f}}{k_{f}}=\left(\frac{\phi_{1} k_{1}+\phi_{2} k_{2}}{\phi}+2 k_{f}+2\left(\phi_{1} k_{1}+\phi_{2} k_{2}\right)-2 \phi k_{f}\right) \\
\times\left(\frac{\phi_{1} k_{1}+\phi_{2} k_{2}}{\phi}+2 k_{f}-\left(\phi_{1} k_{1}+\phi_{2} k_{2}\right) \phi k_{f}\right)^{-1} \\
\left.\frac{\sigma_{\text {hnf }}}{\sigma_{f}}=1+\frac{\left(\phi_{1} \sigma_{1}+\phi_{2} \sigma_{2}\right)}{\sigma_{f}}-\phi\right) \\
\left(\frac{\left(\phi_{1} \sigma_{1}+\phi_{2} \sigma_{2}\right)}{\phi \sigma_{f}}+2\right)-\left(\frac{\left(\phi_{1} \sigma_{1}+\phi_{2} \sigma_{2}\right)}{\sigma_{f}}-\phi\right)
\end{gathered}
$$

where $\phi=\phi_{1}+\phi_{2}$; subscripts of $f$ refer to the base fluid (water).

An imposed magnetic field and vortex viscosity parameters should not depend on $x$ to obtain similarity solutions. So, taking $G r_{x} \sim x^{-2 \lambda+5}$, then $\lambda=0.5$. The suction rate becomes constant at $\lambda=0.5$ and we deduce that the heat flow utilized to the wall is uniform at $\lambda=0.5$.

By substituting Equation (6) into Equations (1)-(4) and with boundary conditions (5) we get:

$$
\begin{gathered}
\frac{\rho_{f}}{\rho_{h n f}}\left(\frac{\mu_{h n f}}{\mu_{f}}+R\right) f^{\prime \prime \prime}=-\frac{\rho_{f}}{\rho_{h n f}} R g^{\prime}-(\lambda+3) f f^{\prime \prime}+2(\lambda+1) f^{\prime 2}-\frac{\beta_{h n f}}{\beta_{f}} \theta+\frac{\rho_{f} \sigma_{h n f}}{\sigma_{f} \rho_{h n f}} M f^{\prime}+\frac{\rho_{f}}{\rho_{h n f}}\left(\frac{\mu_{h n f}}{\mu_{f}}+R\right) \frac{2}{D a} f^{\prime} \\
\frac{\left(\rho C_{p}\right)_{f}}{\left(\rho C_{p}\right)_{h n f}}\left[\left(\frac{4}{3} R d+\frac{k_{h n f}}{k_{f}}\right) \theta^{\prime \prime}+c e^{-\eta}\right]=4 \lambda \operatorname{Pr} \theta f^{\prime}-(\lambda+3) \operatorname{Pr} f \theta^{\prime}, \\
\frac{\rho_{f}}{\rho_{h n f}}\left(\frac{\mu_{h n f}}{\mu_{f}}+\frac{R}{2}\right) g^{\prime \prime}=(1+3 \lambda) f^{\prime} g-(\lambda+3) f g^{\prime}+\frac{\rho_{f}}{\rho_{h n f}} R B\left(f^{\prime \prime}+2 g\right) .
\end{gathered}
$$

The boundary conditions defined in Equations (4) and (5) after transformations become:

$$
\left.\begin{array}{c}
f^{\prime}(0)=0, f(0)=f_{w}, \theta(0)=1, g=-n f^{\prime \prime} \text { at } \eta=0 \\
f^{\prime}(\infty) \rightarrow 0, \theta(\infty) \rightarrow 0, g(\infty)=0 \text { as } \eta=\infty
\end{array}\right\}
$$

Here, the primes indicate the derivate is with respect to $\eta$. IHG and WIHG are also debated, which refers to internal heat generation $(c=1)$ and without internal heat generation $(c=0)$, respectively. The parameters that appear in the above equations are micropolar parameter $R$, magnetic parameter $M$, Darcy number $D a$, radiation parameter $R d$, Prandtl parameter Pr, the vortex of viscosity B and the suction parameters, which are defined as:

$$
\begin{gathered}
R=\frac{k}{\mu_{f}}, M=\frac{\sigma_{f} B_{0}^{2} x^{2}}{\mu_{f}}\left(\frac{G r_{x}}{4}\right)^{-\frac{1}{2}}, D a=\frac{2 K}{x^{2}}\left(\frac{G r}{4}\right)^{\frac{1}{2}}, R d=\frac{4 \sigma^{*} T_{\infty}^{3}}{k^{*} k_{f}}, \operatorname{Pr}=\frac{v_{f}}{\alpha_{f}}, \\
B=\frac{x^{2}}{j}\left(\frac{G r_{x}}{4}\right)^{-\frac{1}{2}}, f_{w}=-\frac{x}{(3+\lambda) v_{f}}\left(\frac{G r_{x}}{4}\right)^{-\frac{1}{4}} v_{w},
\end{gathered}
$$


Finally, the expression of drag friction $\mathrm{Cf}$ and the local Nusselt number (Nux) can be given by:

$$
C f=\frac{\tau_{w}}{\rho_{f} U^{2}}, N u_{x}=\frac{x q_{w}}{k_{f}\left(T_{w}-T_{\infty}\right)},
$$

where $\tau_{w}$ is the surface shear stress (skin friction) and $q_{w}$ is the flow of heat from the surface of the plate, which is defined as:

$$
\tau_{w}=\left[\left(\mu_{h n f}+k\right) \frac{\partial u}{\partial y}+k(N)\right]_{y=0}, q_{w}=-k_{h n f} \frac{\partial T}{\partial y} \mid y=0 .
$$

By using the dimensionless transformation from Equation (6) we have:

$$
\begin{gathered}
4\left(\frac{G r_{x}}{4}\right)^{\frac{1}{4}} C_{f}=\left[\left(\frac{\mu_{h n f}}{\mu_{f}}+(1-n) R\right)\right] f^{\prime \prime}(0), \\
\left(\frac{G r_{x}}{4}\right)^{\frac{-1}{4}} N u_{x}=-\left(\frac{k_{h n f}}{k_{f}}+\frac{4}{3} R d\right) \theta^{\prime}(0) .
\end{gathered}
$$

\section{Adaptive Chebyshev Differential Quadrature Method}

The system of Equations (13)-(16) is a boundary layer problem that has a solution with a rapid change at the left end boundary point. This problem may be solved effectively if the grid points are concentrated in the layer. The Chebyshev differential quadrature method (CDQM) ensures that more collocation points lie in the boundary layer. For more details about the spectral accuracy and convergence of the method see, for example, [15,32,39-50]. It is well-known that the CDQM enhanced with an adaptive grid transformation [47-50] results in more accurate results than the standard CDQM in solving boundary layer problems.

To solve the ODE system (13)-(16), we used the ACDQM [48-50] using the Lagrange interpolation polynomial as our based functions over the transformed Chebyshev-GaussLobatto grid points defined by [15,48-50]:

$$
\eta_{j}=\frac{-1}{2}\left[\delta_{0} \sinh \left(\frac{\hat{k}}{2}\left(1-\cos \frac{j \pi}{N_{\bar{\eta}_{\infty}}-1}\right)\right)\right] \bar{\eta}_{\infty}
$$

where $j=0,1, \ldots N_{\bar{\eta}_{\infty}}-1, \widehat{k}=\sinh ^{-1}\left(2 / \delta_{0}\right), \delta_{0}$ is the boundary layer width, $\bar{\eta}_{\infty}$ is the initial estimation of $\eta_{\infty}$ and $N_{\bar{\eta}_{\infty}}$ is the number of grid points over $\eta \in\left[0, \bar{\eta}_{\infty}\right]$.

Applying the ACDQM on system (13)-(16) results in:

$$
\begin{gathered}
a_{i}=\check{A} \sum_{j=0}^{N_{\bar{\eta}_{\infty}}-1} \mathrm{~d}_{i, j}^{(3)} f_{j}+\frac{\rho_{f}}{\rho_{h n f}} R \sum_{j=0}^{N_{\bar{\eta}_{\infty}}-1} \mathrm{~d}_{i, j}^{(1)} g_{j}+(\lambda+3) f_{j} \cdot \sum_{j=0}^{N_{\bar{\eta}_{\infty}}-1} \mathrm{~d}_{i, j}^{(2)} f_{j}-2(\lambda+1)\left(\sum_{j=0}^{N_{\bar{\eta}_{\infty}}-1} \mathrm{~d}_{i, j}^{(1)} f_{j}\right)^{2}+ \\
\frac{\beta_{h n f}}{\beta_{f}} \sum_{j=0}^{N_{\bar{\eta}_{\infty}}-1} \mathrm{~d}_{i, j}^{(1)} \theta_{j}-\left(\check{A} \frac{2}{D a}+\frac{\rho_{f} \sigma_{h n f}}{\sigma_{f} \rho_{h n f}} M\right) \sum_{j=0}^{N_{\bar{\eta}_{\infty}}-1} \mathrm{~d}_{i, j}^{(1)} f_{j}=0, \\
b_{i}=\frac{\left(\rho C_{p}\right)_{f}}{\left(\rho C_{p}\right)_{h n f}}\left[\left(\frac{4}{3} R d+\frac{K_{h n f}}{K_{f}}\right) \sum_{j=0}^{N_{\bar{\eta}_{\infty}}-1} \mathrm{~d}_{i, j}^{(2)} \theta_{j}+e^{-\eta_{j}}\right]-4 \lambda \operatorname{Pr} \sum_{j=0}^{N_{\bar{\eta}_{\infty}}-1} \mathrm{~d}_{i, j}^{(1)} f_{j} \cdot \theta_{j}+(\lambda+3) \operatorname{Pr} \sum_{j=0}^{N_{\bar{\eta}_{\infty}}-1} \mathrm{~d}_{i, j}^{(1)} \theta_{j} \cdot f_{j}=0, \\
c_{i}=\frac{\rho_{f}}{\rho_{h n f}}\left(\frac{\mu_{h n f}}{\mu_{f}}+\frac{R}{2}\right) \sum_{j=0}^{N_{\bar{\eta}_{\infty}}-1} \mathrm{~d}_{i, j}^{(2)} g_{j}-(1+3 \lambda) \sum_{j=0}^{N_{\bar{\eta}_{\infty}}-1} \mathrm{~d}_{i, j}^{(1)} f_{j} \cdot g_{j}+(\lambda+3) \sum_{j=0}^{N_{\bar{\eta}_{\infty}}-1} \mathrm{~d}_{i, j}^{(1)} g_{j} f_{j}- \\
\frac{\rho_{f}}{\rho_{h n f}} R B\left(\sum_{j=0}^{N_{\bar{m}_{\infty}}-1} \mathrm{~d}_{i, j}^{(2)} f_{j}+2 g_{j}\right)=0,
\end{gathered}
$$




$$
\left.\begin{array}{c}
f^{\prime}(0)=\sum_{j=0}^{N_{\bar{\eta}_{\infty}}-1} \mathrm{~d}_{0, j}^{(1)} f_{j}=0, \quad f(0)=\sum_{j=0}^{N_{\bar{\eta}_{\infty}}-1} I_{0, j} f_{j}=f_{w} \\
\theta(0)=\sum_{j=0}^{N_{\bar{\eta}_{\infty}}-1} I_{0, j} \cdot \theta_{j}=1, \sum_{j=0}^{N_{\bar{\eta}_{\infty}}-1} I_{N_{\bar{\eta}_{\infty}}-1, j} g_{j}=-n \sum_{j=0}^{N_{\bar{\eta}_{\infty}}-1} \mathrm{~d}_{N_{\bar{\eta}_{\infty}}-1, j}^{(2)} f_{j} \\
f^{\prime}(\infty)=\sum_{j=0}^{N_{\bar{\eta}_{\infty}}-1} \mathrm{~d}_{N_{\bar{\eta}_{\infty}}-1, j}^{(1)} f_{j}=0, \theta(\infty)=\sum_{j=0}^{N_{\bar{\eta}_{\infty}}-1} I_{N_{\bar{\eta}_{\infty}}-1, j} \cdot \theta_{j}=0, g(\infty)=\sum_{j=0}^{N_{\bar{\eta}_{\infty}}-1} I_{N_{\bar{\eta}_{\infty}}-1, j} \cdot g_{j}=0
\end{array}\right\}
$$

where $\check{A}=\frac{\rho_{f}}{\rho_{h n f}}\left(\frac{\mu_{h n f}}{\mu_{f}}+R\right), i=0,1, \ldots, N_{\bar{\eta}_{\infty}}-1, \mathrm{~d}_{i, j}^{(m)}$ and $m=1,2,3$ are the $j$ elements of the $i$ row of the $m^{\text {th }}$ derivatives of the Chebyshev differentiation matrices defined in $[15,40-50]$ and transformed using (22) [48-50]; $I_{0, j}$ is the first row of the identity matrix of order $j$.

Thus, the system (13)-(16) is transformed into a non-linear algebraic system of $3 N_{\bar{\eta}_{\infty}}$ equations in $3 N_{\bar{\eta}_{\infty}}$ unknowns and can be written in a vector form as follows.

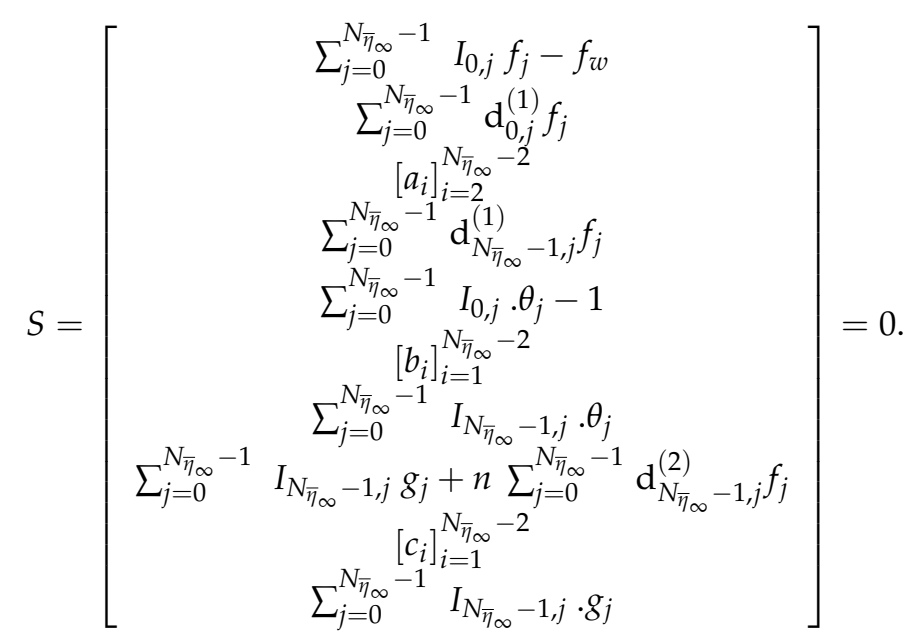

The non-linear algebraic system (27) is solved using the MATLAB built in function fsolve with absolute and relative tolerances $10^{-12}$ and $10^{-5}$, respectively, using an initial guess solution that satisfies the boundary conditions (16) and given by:

$$
\left.\begin{array}{c}
f(\eta)=f_{w}-e^{-\eta}(1+\eta)+1 \\
\theta(\eta)=e^{-\eta} \\
g(\eta)=n\left(\eta e^{-\eta}-e^{-\eta}\right)
\end{array}\right\} .
$$

To ensure the efficiency of the present method, the results that we obtained are compared with the results that Ferdows and Liu obtained [43], for the special case $(\lambda=1$, $\left.M=2, n=0.5, f_{w}=0.5, P r=0.1, \phi=0\right)$, as shown in Table 2. Results in Table 2 show a very good agreement between the results. Moreover, the maximum absolute error for the solutions obtained using the CDQM and $\mathrm{ACDQM}$ are presented in Figure 2a,b considering the numerical solution obtained using the built in MATLAB solver bvp4c with absolute and relative tolerances $10^{-20}$ and $10^{-8}$, respectively, as our reference solutions. As shown in Figure 2, the ACDQM results in a more accurate solution than the CDQM and achieves a high accuracy is obtained even at a low number of grid points. 
Table 2. Comparison of $f^{\prime \prime}(0)$ and $-\theta^{\prime}(0)$ for various values of the micropolar parameter $R$ when $\left(\lambda=1, M=2, n=0.5, f_{w}=0.5, \operatorname{Pr}=0.1\right)$.

\begin{tabular}{ccccccccc}
\hline & \multicolumn{3}{c}{ Ferdows et al. [33] } & \multicolumn{3}{c}{ Present Study } \\
\cline { 2 - 9 } $\boldsymbol{R}$ & \multicolumn{2}{c}{$\boldsymbol{f}^{\prime \prime}(\mathbf{0})$} & \multicolumn{2}{c}{$-\boldsymbol{\theta ( 0 )}$} & \multicolumn{2}{c}{$f^{\prime \prime}(\mathbf{0})$} & \multicolumn{2}{c}{$-\boldsymbol{\theta}^{\prime} \mathbf{( 0 )}$} \\
& IHG & WHG & IHG & WIHG & IHG & WIHG & IHG & WIHG \\
\hline 0 & 0.9564 & 0.7464 & -0.3486 & 0.402 & 0.9564 & 0.7464 & -0.3486 & 0.4020 \\
0.25 & 0.879 & 0.6804 & -0.353 & 0.3991 & 0.8791 & 0.6804 & -0.3531 & 0.3991 \\
0.5 & 0.8169 & 0.6278 & -0.3571 & 0.3963 & 0.8169 & 0.6278 & -0.3570 & 0.3963 \\
\hline
\end{tabular}

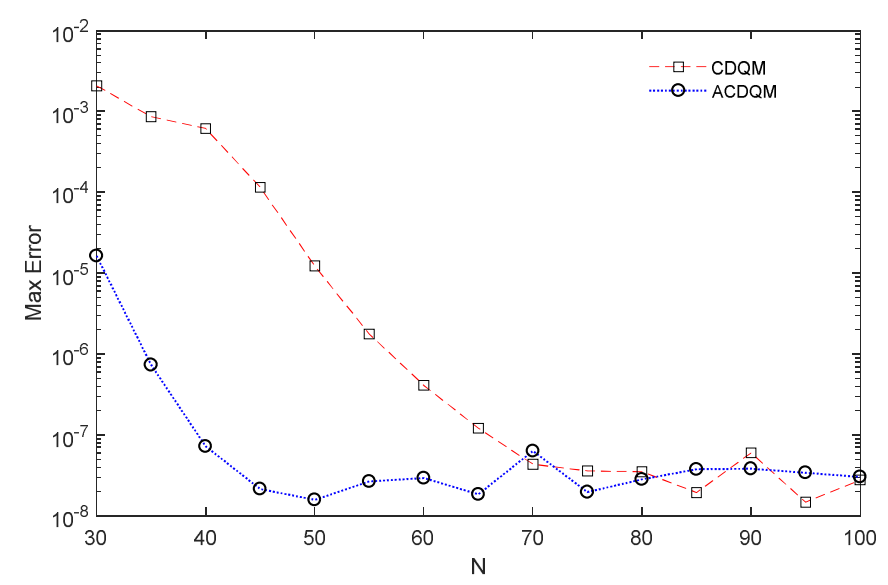

(a)

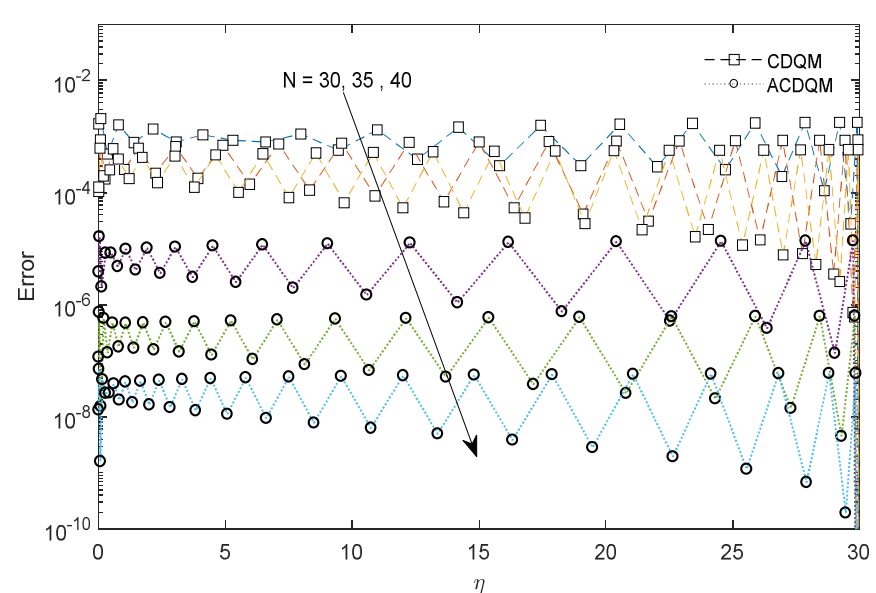

(b)

Figure 2. Maximum absolute error versus the number of grid points (a) and the absolute error distribution overall in the problem domain (b) at $N=30,35,40$ for the CDQM and ACQDM at $R=0.5, M=1, \lambda=0.5, c=1, \mathrm{~B}=0.2, \phi_{1}=\phi_{2}=$ $0.1, D a=1 ; R d=1, n=0.5$.

\section{Results and Discussion}

In this section, the numerical results obtained using the ACDQM are presented to study the impact of the magneto-natural convection flow of the micropolar hybrid nanoliquid $\left(\mathrm{Al}_{2} \mathrm{O}_{3}-\mathrm{Cu} /\right.$ water $)$ saturated in a porous medium. Table 1 shows the thermophysical properties of water, copper and alumina. For obtaining the physical meaning of the problem, the impacts of the micropolar parameter $(\mathrm{R})$, magnetic field parameter $(\mathrm{M})$, volume fraction parameter $(\phi)$, microrotation parameter $(n)$, radiation parameter $\mathrm{Rd}$, suction Parameter $f_{w}$ and Darcy number (Da) on the skin friction parameter, Nusselt number, angular velocity, temperature and the velocity profiles were explained.

Figure $3 \mathrm{a}-\mathrm{c}$ manifest the effect of the suction parameter $f_{w}$ on velocity, temperature and angular velocity profiles of the hybrid nanofluid. As evidenced from these Figures, the angular velocity profiles were boosted with the increasing values of the suction parameter $f_{w}$ unlike the velocity and temperature profiles, which decreased. Thus, we could control the velocity of the flow by suction, which is significant for many applications in engineering. The internal heat generation decreased the velocity and thickness of the boundary layer and we believed that this finding was important because it could not expound on a physical basis easily. The fluid wall suction application $\left(f_{w}>0\right)$ could decrease much of the density of fluid, temperature and micro-rotation in an equal way as the thickness of the boundary layer. 


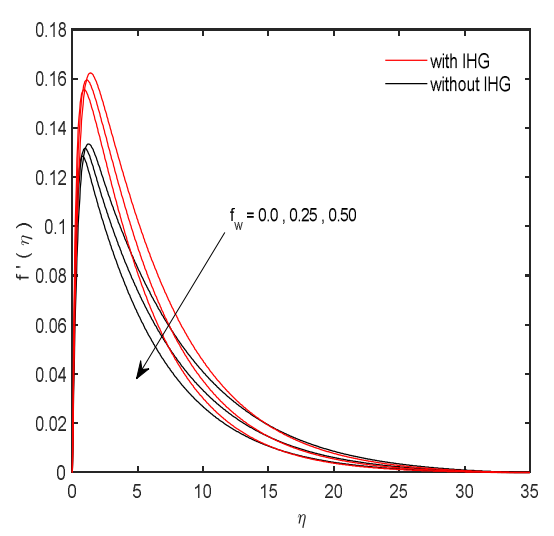

(a)

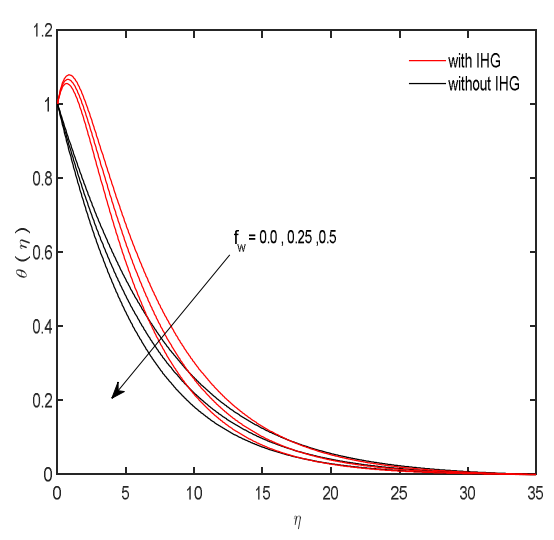

(b)

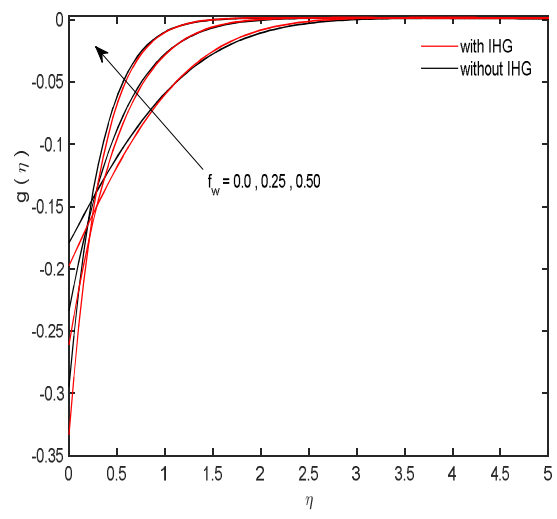

(c)

Figure 3. The effect of the suction parameter $f_{w}$ on the (a) velocity profile, (b) temperature profile and (c) angular velocity profile for $R=0.5, M=2, \lambda=0.5, c=1, \mathrm{~B}=0.2, \phi_{1}=\phi_{2}=0.05, D a=1 ; R d=1, n=0.5$.

The effect of the micropolar parameter $\mathrm{R}$ on velocity, temperature and the angular velocity profiles of the hybrid nanofluid are displayed in Figure $4 \mathrm{a}-\mathrm{c}$. As shown from these plots, the angular velocity profiles of the hybrid nanofluid were improved with the raised values of the micropolar parameter $R$ unlike the hybrid nanofluid velocity profile, which was decreased as it decreased near the surface of the plate and then increased elsewhere. This was because the acclivity in $R$ created an increase in the fluid's viscosity, which was why the angular velocity increased. The influence of the micropolar parameter $R \operatorname{did}$ not appear clearly in the temperature profile of the hybrid nanofluid because the micropolar parameter $R$ did not exist in energy Equation (14). However, by zooming the curves in the temperature profile we noticed that it was reduced as the micropolar parameter increased.

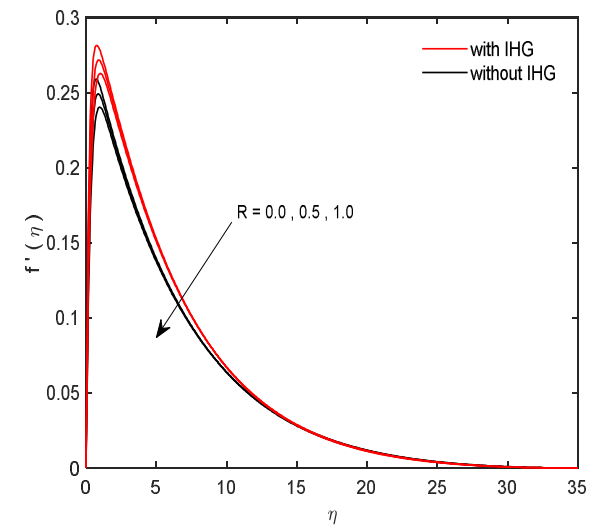

(a)

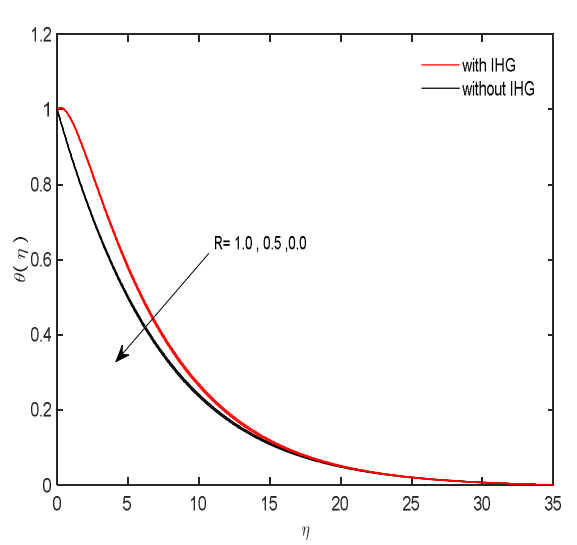

(b)

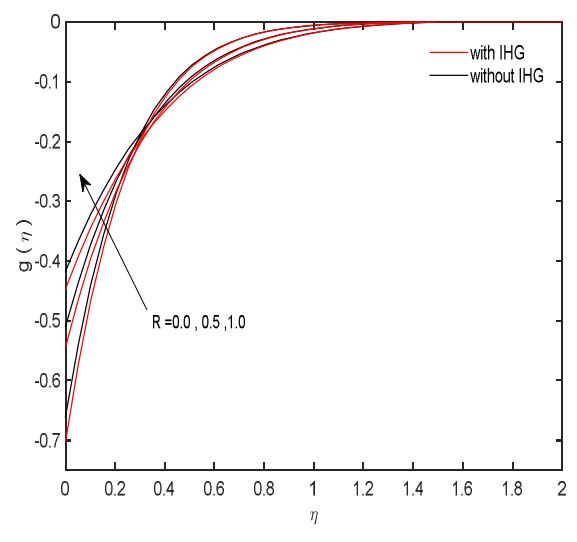

(c)

Figure 4. The effect of the micropolar parameter $R$ on the (a) velocity profile, (b) temperature profile and (c) angular velocity profile for $M=1, \lambda=0.5, c=0, B=0.2, \phi_{1}=\phi_{2}=0.05, D a=10, R d=3, n=0.5, f w=0.5$.

Figure $5 \mathrm{a}-\mathrm{c}$ reflect the effect of the Darcy number $D a$ on the velocity, temperature and angular velocity profiles of the hybrid nanofluid. The growth in $D a$ led to an increase in the velocity profiles of the hybrid nanofluid. The higher the value of the Darcy number $D a$, the more the porous medium's permeability increased. Therefore, resistance to the flow occurred due to the presence of a permeable medium. This resistance slowed down the motion of the fluid and increased the velocity profile unlike the temperature and angular velocity profiles, which decreased by a growth in $D a$. 


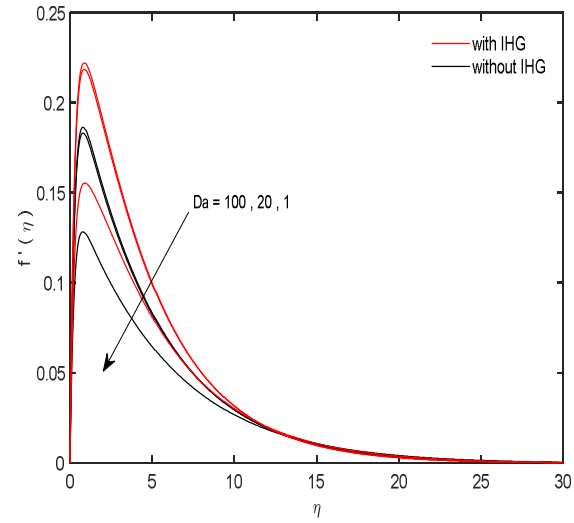

(a)

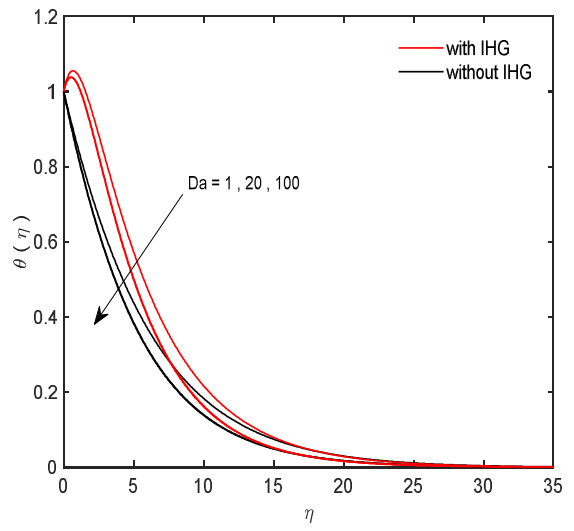

(b)

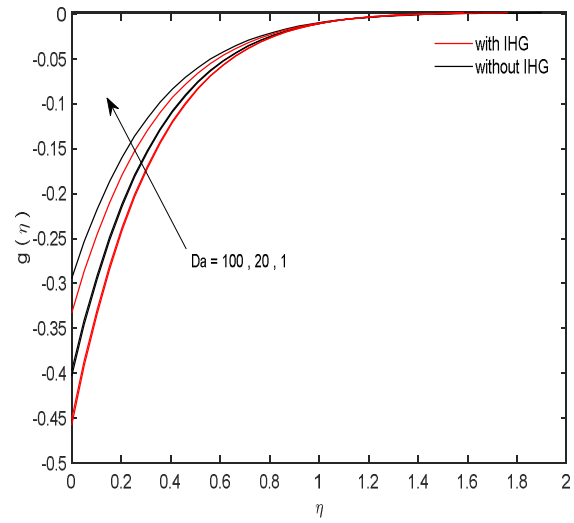

(c)

Figure 5. The effect of the Darcy number $D a$ on the (a) velocity profile, (b) temperature profile and (c) angular velocity profile for $R=0.5, M=2, \lambda=0.5, c=1, B=0.2, \phi_{1}=\phi_{2}=0.05, R d=1, n=0.5, f_{w}=0.5$.

Figure 6a-c are illustrated to show the effect of the magnetic parameter $M$ on velocity, temperature and angular velocity profiles, respectively. It was observed that both the temperature and angular velocity profiles improved with the mounting values of the magnetic parameter $M$ unlike the velocity profile, which declined by increasing the magnetic parameter. Physically, a raise in the magnetic parameter $M$ created a higher drag power (Lorentz force) that transformed some kinetic energy into thermal energy.

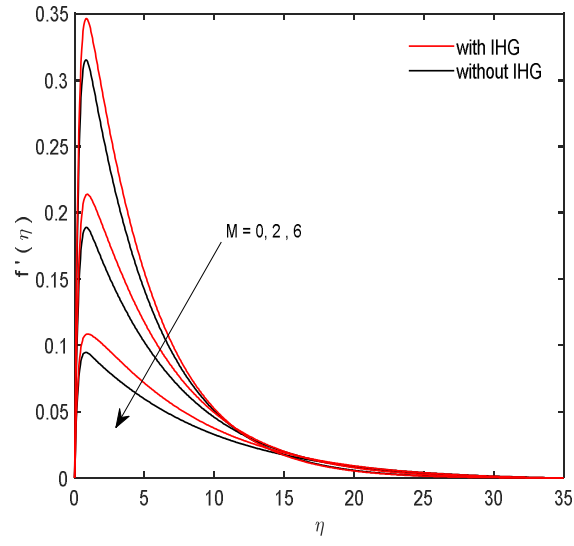

(a)

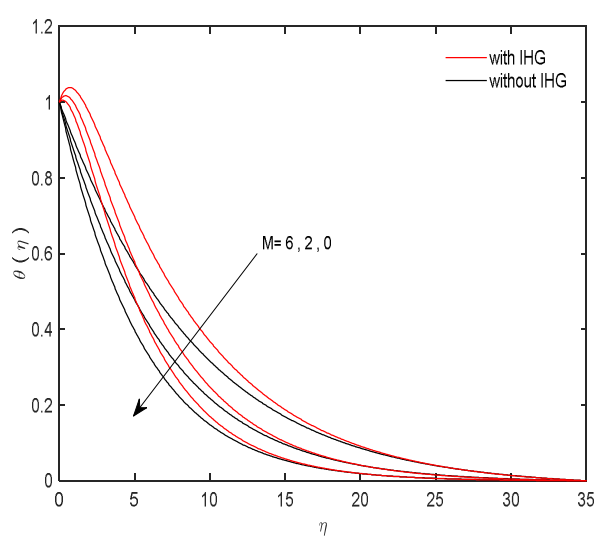

(b)

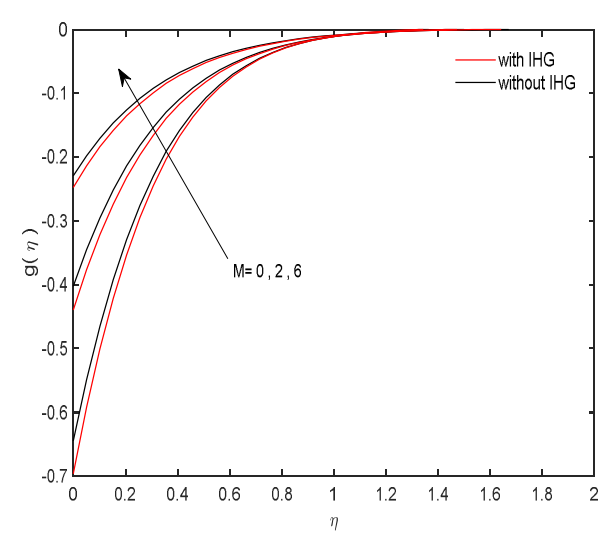

(c)

Figure 6. The effect of the magnetic parameter $M$ on the (a) velocity profile, (b) temperature profile and (c) angular velocity profile for $R=0.5, \lambda=0.5, c=1, B=0.2, \phi_{1}=\phi_{2}=0.05, D a=10, R d=2, n=0.5, f_{w}=0.5$.

The impact of the micro-rotation parameter $n$ on the velocity, temperature and angular velocity profiles of the hybrid nanofluid are submitted in Figure 7a-c, which indicated that as $n$ increased, the velocity profile improved unlike the angular velocity, which decreased. It is clear from Figure $7 \mathrm{~b}$ that the impact of $n$ was not important at all for the WIHG and IHG cases separately but by zooming the curves of the temperature profile it was noticed that it decreased as the micro-rotation parameter $n$ increased. 


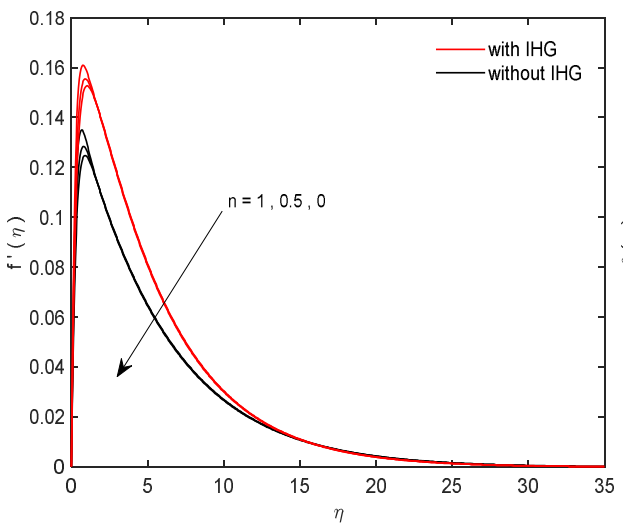

(a)

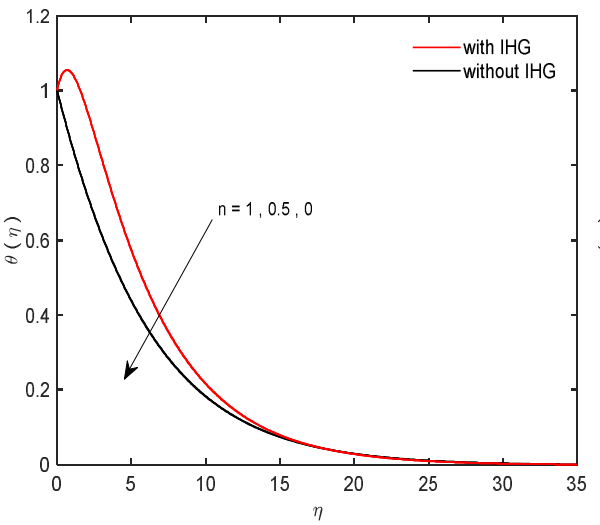

(b)

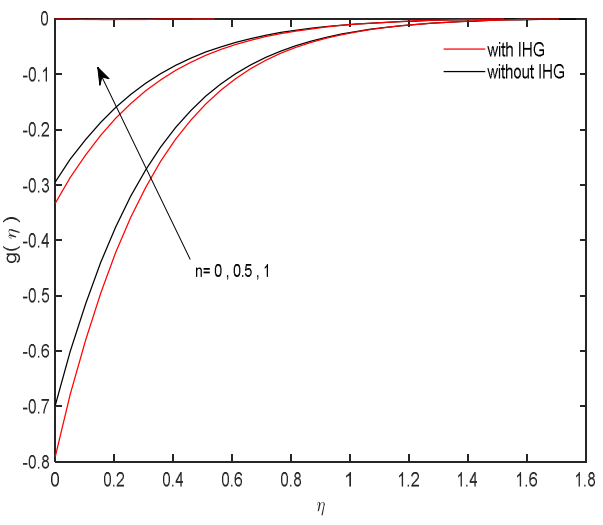

(c)

Figure 7. The effect of the micro-rotation parameter $n$ on the (a) velocity profile, (b) temperature profile and (c) angular velocity profile for $R=0.5, M=2, \lambda=0.5, c=0, B=0.2, \Phi_{1}=\phi_{2}=0.05, D a=1, R d=1, f_{w}=0.5$.

Figure $8 \mathrm{a}-\mathrm{c}$ show the effect of the thermal radiation parameter $R d$ on the velocity, temperature and angular velocity profiles of the hybrid nanofluid. It was clear that the micropolar fluid velocity and temperature profiles improved with the growing values of the thermal radiation parameter while the angular velocity profiles decreased. It was confirmed that the micropolar model was applicable to a small geometrical dimension of the flow especially in the existence of thermal radiation effects. Physically, it confirmed the idea that the radiation process created more heat.

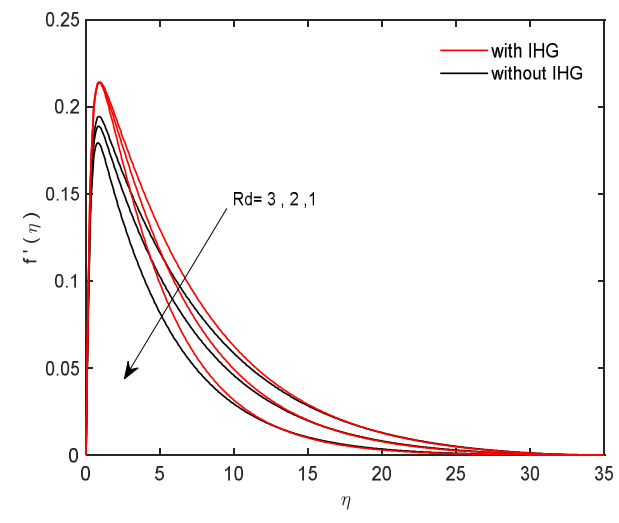

(a)

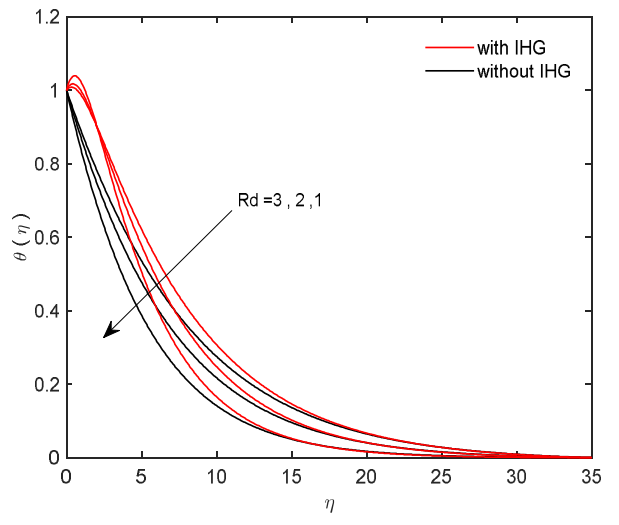

(b)

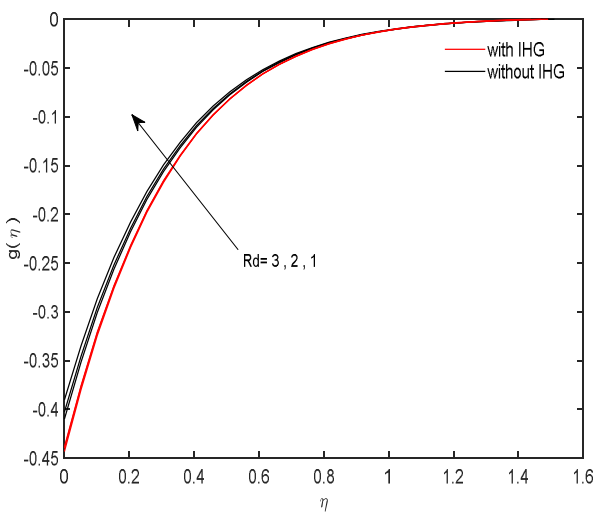

(c)

Figure 8. The effect of the radiation parameter $R d$ on the (a) velocity profile, (b) temperature profile and (c) angular velocity profile for $R=0.5, M=2, \lambda=0.5, c=0, \mathrm{~B}=0.2, \Phi_{1}=\phi_{2}=0.05, D a=10, f_{w}=0.5, n=0.5$.

Finally, the effect of the volume fraction parameter $\phi$ on the velocity, temperature and angular velocity profiles of the hybrid nanofluid are shown in Figure 9a-c. These plots indicated that the velocity profile decreased as the volume fraction parameter $\phi$ raised unlike the temperature and angular velocity. The Figure makes it very clear that a hybrid nanofluid $\left(\mathrm{Al}_{2} \mathrm{O}_{3}-\mathrm{Cu} /\right.$ water $)$ had more thermal conductivity than pure water. Physically, inserting more and various nanoparticles provided energy, which raised the temperature and stiffened the boundary layer of the thermal. This indicated that the nanoparticles created warmth. 


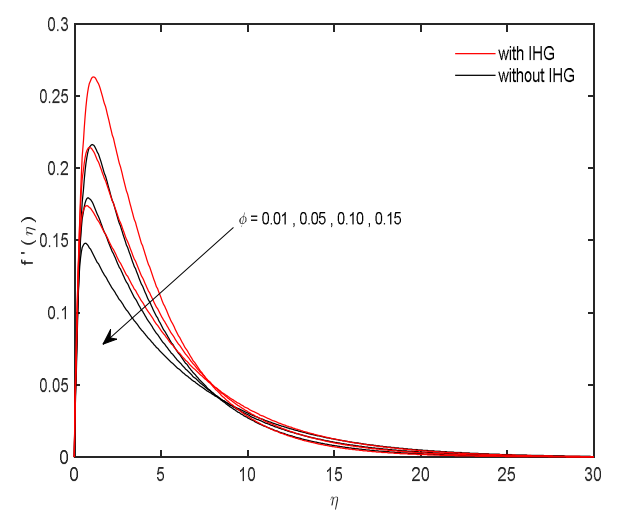

(a)

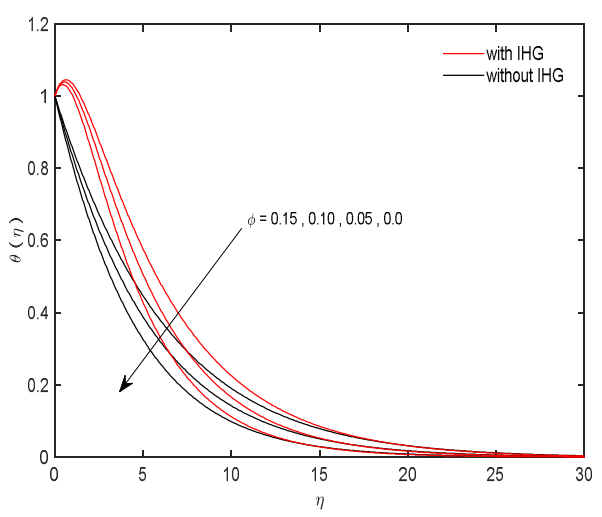

(b)

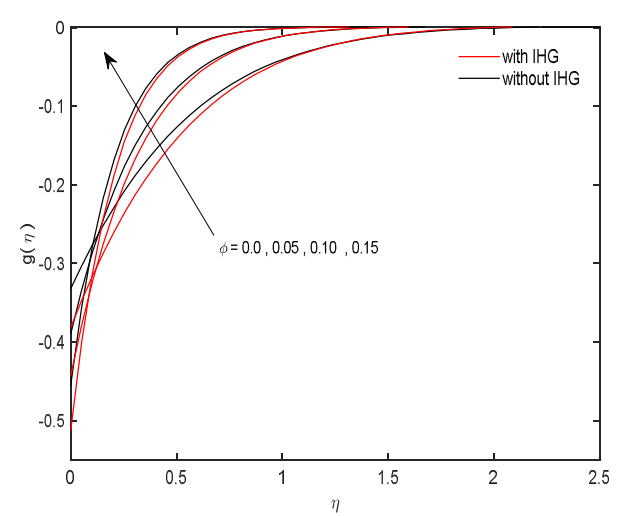

(c)

Figure 9. The effect of the nanoparticle volume friction parameter $\phi$ on the (a) velocity profile, (b) temperature profile and (c) angular velocity profile for $R=0.5, M=2, \lambda=0.5, c=0, B=0.2, D a=(10), R D=1, n=0.5, f w=0.5$.

Table 3 provides the numerical estimate of the skin friction coefficient $4\left(\frac{G r_{x}}{4}\right)^{\frac{1}{4}} C_{f}$ and the Nusselt number $\left(\frac{G r_{x}}{4}\right)^{\frac{-1}{4}} N u_{x}$ for several values of $R, M n, f_{w}, R d, \phi$ and $D a$. It was illustrated that an upsurge in values of the micropolar parameter $R$ encouraged the vortex viscosity of the nanofluid flow, which dropped opposition to rotate the hybrid nanofluid that resulted in reducing the skin friction coefficient and heat transference rate with the IHG and WIHG cases. Moreover, it was reported that the skin friction coefficient improved and the Nusselt number declined by swelling the values of the nanoparticle volume fraction $\phi$. This happened because greater values of $\phi$ yielded a great energy transport through the flow associated with the irregular motion of the nanoparticles and hence produced a slight enhancement in the shear stress with the IHG and WIHG cases and a reduction in the heat transference rate with the IHG and WIHG cases. Furthermore, it was experiential that both the skin friction coefficient and the Nusselt number reduced significantly by strengthening the magnetic parameter $M$. As explored above, this reduction was due to the effect of the Lorentz force. The Lorentz force worked versus the tendency of the flow and consequently yielded a resistance to the flow; this diminution caused a reduction in the skin friction parameter and the Nusselt number. It was also found that a rise in the Darcy number (boosting the porosity of porous media) caused an increase in skin friction and the Nusselt number. By taking several values of the micro-rotation parameter $n$, it was observed that the growth in $n$ resulted in an enhancement in the Nusselt number and a reduction in the skin friction coefficient with the IHG and WIHG cases. Moreover, it was elucidated that both skin friction and the Nusselt number were promoted with the increment in the $R d$. The reason for this tendency could be elucidated as follows: a larger $R d$ produced greater values of temperature at the plate surface. The radiation also worked as a heat exporter and then this heat magnitude, added to the liquid, grew, which resulted in an increment in the heat transference. However, it was demonstrated that the skin friction was always the lowest and the Nusselt number was the highest as the suction parameter increased with the IHG and WIHG cases. This meant that the suction procedure was an effective tool to control the flow dynamics and heat transfer rate. 
Table 3. Skin friction coefficient and the Nusselt number for various values of $R, M, n, f_{w}, R d, \phi$ and $D a$ at $\lambda=0.5, B=0.1$.

\begin{tabular}{|c|c|c|c|c|c|c|c|c|c|c|}
\hline \multirow[t]{2}{*}{1} & \multirow[t]{2}{*}{$M$} & \multirow[t]{2}{*}{$n$} & \multirow[t]{2}{*}{$f_{w}$} & \multirow[t]{2}{*}{$R d$} & \multirow[t]{2}{*}{$\phi$} & \multirow[t]{2}{*}{$D a$} & \multicolumn{2}{|c|}{$4\left(\frac{G r_{x}}{4}\right)^{\frac{1}{4}} C_{f}$} & \multicolumn{2}{|c|}{$\left(\frac{G r_{x}}{4}\right)^{\frac{-1}{4}} N u_{x}$} \\
\hline & & & & & & & IHG & WIHG & IHG & WIHG \\
\hline 0 & 2 & 0.5 & 0.5 & 1 & 0.1 & 1 & 0.7237 & 0.6433 & -0.4505 & 0.4179 \\
\hline 0.5 & & & & & & & 0.6788 & 0.5996 & -0.4807 & 0.3956 \\
\hline 1 & & & & & & & 0.6438 & 0.5664 & -0.5061 & 0.3772 \\
\hline \multirow[t]{3}{*}{0.5} & 0 & 0.5 & 0.5 & 1 & 0.1 & 1 & 0.9542 & 0.8401 & -0.3963 & 0.4589 \\
\hline & 2 & & & & & & 0.6788 & 0.5996 & -0.4807 & 0.3956 \\
\hline & 6 & & & & & & 0.4395 & 0.3950 & -0.5761 & 0.3289 \\
\hline \multirow[t]{3}{*}{0.5} & 2 & 0 & 0.5 & 1 & 0.1 & 1 & 0.7313 & 0.6460 & -0.4833 & 0.3932 \\
\hline & & 0.5 & & & & & 0.6788 & 0.5996 & -0.4807 & 0.3956 \\
\hline & & 1 & & & & & 0.6070 & 0.5362 & -0.4771 & 0.3988 \\
\hline \multirow[t]{3}{*}{0.5} & 2 & 0.5 & 0 & 1 & 0.1 & 1 & 0.4023 & 0.3646 & -0.5544 & 0.2980 \\
\hline & & & 0.25 & & & & 0.5314 & 0.4756 & -0.5194 & 0.3450 \\
\hline & & & 0.5 & & & & 0.6788 & 0.5996 & -0.4807 & 0.3956 \\
\hline \multirow[t]{3}{*}{0.5} & 2 & 0.5 & 0.5 & 1 & 0.1 & 1 & 0.6788 & 0.5996 & -0.4807 & 0.3956 \\
\hline & & & & 2 & & & 0.6686 & 0.6139 & -0.4250 & 0.4687 \\
\hline & & & & 3 & & & 0.6639 & 0.6219 & -0.3737 & 0.5314 \\
\hline \multirow[t]{3}{*}{0.5} & 2 & 0.5 & 0.5 & 1 & 0.05 & 1 & 0.6760 & 0.5948 & -0.4698 & 0.3998 \\
\hline & & & & & 0.1 & & 0.6788 & 0.5996 & -0.4807 & 0.3956 \\
\hline & & & & & 0.15 & & 0.6797 & 0.6010 & -0.4925 & 0.3903 \\
\hline \multirow[t]{3}{*}{0.5} & 2 & 0.5 & 0.5 & 1 & 0.1 & 1 & 0.6788 & 0.5996 & -0.4807 & 0.3956 \\
\hline & & & & & & 20 & 0.9187 & 0.8087 & -0.4060 & 0.4514 \\
\hline & & & & & & 100 & 0.9325 & 0.8208 & -0.4022 & 0.4543 \\
\hline
\end{tabular}

\section{Conclusions}

This numerical simulation reflected the magneto-natural convection flow of a micropolar hybrid nanoliquid past an orthogonal radiative plate statured in a porous medium. The base fluid was taken as water while the micropolar hybrid nanofluid was considered to be copper combined with alumina nanoparticles. Non-dimensional factors were exploited to transmute the governing PDEs into ordinary ones. The transmuted model subject to analogous BCs was then solved numerically with the help of the ACDQM. The influences of the prominent parameters on velocity, angular velocity and temperature fields as well as the skin friction coefficient and the Nusselt number were visualized and analyzed through graphs and tabular forms. The main achieved results were as follows:

- As the micropolar parameter boosted the skin friction coefficient, the Nusselt number diminished with the IHG and WIHG cases.

- $\quad$ Both the skin friction coefficient and the Nusselt number magnified with upsurging in the Darcy number whilst the opposite impact occurred with the growth in the micro-rotation parameter.

- The thermal radiation parameter contributed to ensuing that the skin friction coefficients and heat transport rates were ever-growing.

- The skin friction coefficient improved and the Nusselt number declined by swelling the values of the nanoparticle volume fraction.

- Both the skin friction coefficient and the Nusselt number declined significantly by strengthening the magnetic force. 
- A growth in the suction parameter yielded a sufficient enhancement in the Nusselt number and the skin friction coefficient with the IHG and WIHG cases.

Author Contributions: Conceptualization, A.M., A.M.R. and W.S.; Methodology, E.R.E.-Z., A.M., A.M.R., W.S. and H.S.A.-J.; Formal analysis, A.M., A.M.R. and W.S.; Investigation, E.R.E.-Z., A.M., A.M.R., W.S. and H.S.A.-J.; Resources, A.M., A.M.R. and W.S.; Writing—original draft preparation, E.R.E.-Z., A.M., A.M.R., W.S. and H.S.A.-J.; Writing-review and editing, E.R.E.-Z., A.M., A.M.R., W.S. and H.S.A.-J.; Supervision, A.M. and A.M.R.; Project administration, A.M. and A.M.R.; Funding acquisition, A.M.R., E.R.E.-Z. and H.S.A.-J. All authors have read and agreed to the published version of the manuscript.

Funding: Not applicable.

Institutional Review Board Statement: Not applicable.

Informed Consent Statement: Not applicable.

Data Availability Statement: Not applicable.

Acknowledgments: The authors acknowledge that this publication was supported by the Deanship of Scientific Research at Prince Sattam bin Abdulaziz University, Alkharj, Saudi Arabia.

Conflicts of Interest: The authors declare no conflict of interest.

\section{Nomenclature}

$\begin{array}{ll}B_{0} & \text { Magnetic field strength } \\ c_{p} & \text { Heat capacity } \\ D a & \text { Darcy number } \\ g & \text { Dimensionless angular velocity } \\ g^{*} & \text { Gravity } \\ G r & \text { Grashof number } \\ j & \text { Density of micro-inertia } \\ K & \text { Permeability } \\ M & \text { Magnetic parameter } \\ N & \text { Dimensional angular velocity } \\ n & \text { Micro-rotation parameter } \\ P r & \text { Prandtl number } \\ q r & \text { Radiation heat flux } \\ q^{\prime \prime \prime} & \text { Heat generation } \\ R & \text { Micropolar parameter } \\ R d & \text { Radiation parameter } \\ T & \text { Dimensional temperature } \\ (u, v) & \text { Velocity components } \\ (x, y) & \text { Dimensional coordinates } \\ \text { Greek symbols } \\ \rho & \text { Density of the fluid } \\ \gamma & \text { Viscosity of spin gradient } \\ \sigma^{*} & \text { Stefan-Boltzmann constant } \\ \kappa^{*} & \text { Coefficients of mean absorption } \\ \phi & \text { Solid volume fraction } \\ \sigma & \text { Coefficient conductivity for electricity } \\ \psi & \text { Stream function } \\ \mu & \text { Effective dynamic viscosity } \\ \beta & \text { Volumetric expansion coefficient } \\ \theta & \text { Dimensionless temperature } \\ \text { Subscripts } \\ w & \text { Conditions at the surface } \\ f & \text { Base fluid } \\ & \end{array}$




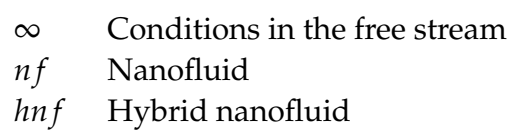

\section{References}

1. Nield, D.A.; Bejan, A. Convection in Porous Media; Springer: New York, NY, USA, 2013.

2. Ingham, D.B.; Pop, I. Transport Phenomena in Porous Media III; Elsevier: Oxford, UK, 2005.

3. Vafai, K. Porous Media: Applications in Biological Systems and Biotechnology; CRC Press: Tokyo, Japan, 2010.

4. Choi, S.U.S. Enhancing thermal conductivity of fluids with nanoparticle, Developments and Applications of Non-Newtonian Flows. ASME FED 1995, 231, 99-105.

5. $\quad$ Eastman, J.A.; Choi, U.S.; Li, S.; Thompson, L.J.; Lee, S. Enhanced Thermal Conductivity through the Development of Nanofluids. MRS Proc. 1996, 457, 3-11. [CrossRef]

6. Buongiorno, J. Convective Transport in Nanofluids. J. Heat Transf. 2006, 128, 240-250. [CrossRef]

7. Chamkha, A.; Rashad, A. Natural convection from a vertical permeable cone in a nanofluid saturated porous media for uniform heat and nanoparticles volume fraction fluxes. Int. J. Numer. Methods Heat Fluid Flow 2012, 22, 1073-1085. [CrossRef]

8. Chamkha, A.J.; Rashad, A.M.; Aly, A.M. Transient natural convection flow of a nanofluid over a vertical cylinder. Meccanica 2012, 48, 71-81. [CrossRef]

9. Rashad, A.M. Natural convection boundary layer flow along a sphere embedded in a porous medium filled with a nanofluid. Lat. Am. Appl. Res. 2014, 44, 149-157.

10. El-Kabeir, S.M.M.; Chamkha, A.J.; Rashad, A.M. The effect of thermal radiation on non-darcy free convection from a vertical cylinder embedded in a nanofluid porous media. J. Porous Media 2014, 17, 269-278. [CrossRef]

11. Chamkha, A.J.; Rashad, A.M.; Reddy, C.R.; Murthy, P.V.S.N. Effect of suction/injection on free convection along a vertical plate in a nanofluid saturated non-Darcy porous medium with internal heat generation. Indian J. Pure Appl. Math. 2014, 45, 321-342. [CrossRef]

12. Rashad, A. Impact of thermal radiation on MHD slip flow of a ferrofluid over a non-isothermal wedge. J. Magn. Magn. Mater. 2017, 422, 25-31. [CrossRef]

13. Sandeep, N.; Chamkha, A.J.; Animasaun, I.L. Numerical exploration of magnetohydrodynamic nanofluid flow suspended with magnetite nanoparticles. J. Braz. Soc. Mech. Sci. Eng. 2017, 39, 3635-3644. [CrossRef]

14. Dogonchi, A.; Sheremet, M.A.; Pop, I.; Ganji, D. MHD natural convection of $\mathrm{Cu} / \mathrm{H}_{2} \mathrm{O}$ nanofluid in a horizontal semi-cylinder with a local triangular heater. Int. J. Numer. Methods Heat Fluid Flow 2018, 28, 2979-2996. [CrossRef]

15. El-Zahar, E.R.; Rashad, A.M.; Seddek, L.F. The Impact of Sinusoidal Surface Temperature on the Natural Convective Flow of a Ferrofluid along a Vertical Plate. Mathematics 2019, 7, 1014. [CrossRef]

16. Nabwey, H.A.; Khan, W.A.; Rashad, A.M. Lie Group Analysis of Unsteady Flow of Kerosene/Cobalt Ferrofluid Past A Radiated Stretching Surface with Navier Slip and Convective Heating. Mathematics 2020, 8, 826. [CrossRef]

17. Ghadikolaei, S.; Yassari, M.; Sadeghi, H.; Hosseinzadeh, K.; Ganji, D. Investigation on thermophysical properties of Tio $2-\mathrm{Cu} / \mathrm{H}_{2} \mathrm{O}$ hybrid nanofluid transport dependent on shape factor in MHD stagnation point flow. Powder Technol. 2017, 322, 428-438. [CrossRef]

18. El-Kabeir, S.M.M.; El-Zahar, E.R.; Modather, M.; Gorla, R.S.R.; Rashad, A.M. Unsteady MHD slip flow of a ferrofluid over an impulsively stretched vertical surface. AIP Adv. 2019, 9, 045112. [CrossRef]

19. Wei, B.; Zou, C.; Yuan, X.; Li, X. Thermo-physical property evaluation of diathermic oil based hybrid nanofluids for heat transfer applications. Int. J. Heat Mass Transf. 2017, 107, 281-287. [CrossRef]

20. Suresh, S.; Venkitaraj, K.P.; Selvakumar, P.; Chandrasekar, M. Synthesis of $\mathrm{Al}_{2} \mathrm{O}_{3}-\mathrm{Cu} /$ Water Hybrid Water-Based Suspensions Using Two Step Method and Its Thermo Physical Properties. Colloids Surf. A Physicochem. Eng. Asp. 2011, 388, 41-48. [CrossRef]

21. Ho, C.; Huang, J.; Tsai, P.; Yang, Y. On laminar convective cooling performance of hybrid water-based suspensions of $\mathrm{Al}_{2} \mathrm{O}_{3}$ nanoparticles and MEPCM particles in a circular tube. Int. J. Heat Mass Transf. 2011, 54, 2397-2407. [CrossRef]

22. Eringen, A.C. Theory of micropolar fluid. J. Math. Mech. 1966, 16, 1-18. [CrossRef]

23. Ariman, T.; Turk, M.A.; Sylvester, N.D. Microcontinuum fluid mechanics-A review. Int. J. Eng. Sci. 1973, 11, 905-930. [CrossRef]

24. Ahuja, A.S. Augmentation of heat transport in laminar flow of polystyrene suspensions. I. Experiments and results. J. Appl. Phys. 1975, 46, 3408-3416. [CrossRef]

25. Bourantas, G.; Loukopoulos, V. MHD natural-convection flow in an inclined square enclosure filled with a micropolar-nanofluid. Int. J. Heat Mass Transf. 2014, 79, 930-944. [CrossRef]

26. Bourantas, G.; Loukopoulos, V. Modeling the natural convective flow of micropolar nanofluids. Int. J. Heat Mass Transf. 2014, 68, 35-41. [CrossRef]

27. Rashad, A.M.; Khan, W.A.; El-Kabeir, S.M.M.; El-Hakiem, A.M.A. Mixed Convective Flow of Micropolar Nanofluid across a Horizontal Cylinder in Saturated Porous Medium. Appl. Sci. 2019, 9, 5241. [CrossRef]

28. Rashad, A.M.; Khan, W.; Tlili, I.; EL-Hakiem, A.M.A. Unsteady slip flow of a micropolar nanofluid over an impulsively stretched vertical surface. Indian J. Pure Appl. Phys. 2019, 57, 773-782.

29. Suresh, K.; Venkitaraj, P.; Chandrasekar, S.M. Effect of $\mathrm{Al}_{2} \mathrm{O}_{3}-\mathrm{Cu}$ /water hybrid nanofluid in heat transfer. Exp. Therm. Fluid Sci. 2012, 38, 54-60. [CrossRef] 
30. Rashad, A.M.; Chamkha, A.J.; Ismael, M.; Salah, T. Magnetohydrodynamics natural convection in a triangular cavity flled with a Cu- $\mathrm{Al}_{2} \mathrm{O}_{3} /$ Water hybrid nanofuid with localized heating from below and internal heat generation. J. Heat Transf. 2018, 140, 072502-13. [CrossRef]

31. Mahdy, A.; Nabwey, H.A. Transient flow of micropolar dusty hybrid nanofluid loaded with $\mathrm{Fe}_{3} \mathrm{O}_{4}$-Ag nanoparticles through a porous stretching sheet have been studied. Results Phys. 2021, 21, 1-11.

32. EL-Zahar, E.R.; Rashad, A.M.; Saad, W.; Seddek, L.F. Magneto-Hybrid Nanofuids Flow via Mixed Convection past a Radiative Circular Cylinder. Sci. Rep. 2020, 10, 10494. [CrossRef] [PubMed]

33. El-Kabeir, S.; Rashad, A.; Khan, W.; Abdelrahman, Z.M. Micropolar ferrofluid flow via natural convective about a radiative isoflux sphere. Adv. Mech. Eng. 2021, 13,1-10. [CrossRef]

34. Ferdows, M.; Liu, D. Natural convective flow of a magneto-micropolar fluid along a vertical plate. Propuls. Power Res. 2018, 7, 43-51. [CrossRef]

35. Jena, S.K.; Mathur, M.N. Similarity solutions for laminar free convective flow of a thermomicropolar fluid past a non isothermal vertical plate. Int. J. Eng. Sci. 1981, 19, 1431-1439. [CrossRef]

36. Ahmadi, G. Self-similar solution of incompressible micropolar boundary layer flow over a semi-infinite plate. Int. J. Eng. Sci. 1976, 14, 639-646. [CrossRef]

37. Peddieson, J. An application of the micropolar fluid model to the calculation of a turbulent shear flow. Int. J. Eng. Sci. 1972, 10, 23-32. [CrossRef]

38. Ho, C.; Huang, J.; Tsai, P.; Yang, Y. Preparation and properties of hybrid water-based suspension of $\mathrm{Al}_{2} \mathrm{O}_{3}$ nanoparticles and MEPCM particles as functional forced convection fluid. Int. Commun. Heat Mass Transf. 2010, 37, 490-494. [CrossRef]

39. Ho, C.; Liu, W.; Chang, Y.; Lin, C. Natural convection heat transfer of alumina-water nanofluid in vertical square enclosures: An experimental study. Int. J. Therm. Sci. 2010, 49, 1345-1353. [CrossRef]

40. Bert, C.W.; Malik, M. Differential Quadrature Method in Computational Mechanics: A Review. Appl. Mech. Rev. 1996, 49, 1-28. [CrossRef]

41. Shu, C. Differential Quadrature and Its Application in Engineering; Springer Science and Business Media LLC: Berlin/Heidelberg, Germany, 2000.

42. Zong, Z.; Zhang, Y. Advanced Differential Quadrature Methods; Chapman and Hall/CRC: London, UK, 2009.

43. Jiwari, R.; Gupta, R.; Kumar, V. Polynomial differential quadrature method for numerical solutions of the generalized FitzhughNagumo equation with time-dependent coefficients. Ain Shams Eng. J. 2014, 5, 1343-1350. [CrossRef]

44. Korkmaz, A.; Dag, I. Polynomial based differential quadrature method for numerical solution of nonlinear Burgers' equation. $J$. Frankl. Inst. 2011, 348, 2863-2875. [CrossRef]

45. Mohammed, O.H.; Saeed, M.A. Numerical solution of thin plates problem via differential quadrature method using G-spline. J. King Saud Univ. Sci. 2019, 31, 209-214. [CrossRef]

46. Ragb, O.; Seddek, L.; Matbuly, M. Iterative differential quadrature solutions for Bratu problem. Comput. Math. Appl. 2017, 74, 249-257. [CrossRef]

47. Tang, T.; Trummer, M.R. Boundary Layer Resolving Pseudospectral Methods for Singular Perturbation Problems. SIAM J. Sci. Comput. 1996, 17, 430-438. [CrossRef]

48. Chen, S.; Wang, Y.; Wu, X. Rational Spectral Collocation Method for a Coupled System of Singularly Perturbed Boundary Value Problems. J. Comput. Math. 2011, 29, 458-473. [CrossRef]

49. Tee, T.W.; Trefethen, L.N. A Rational Spectral Collocation Method with Adaptively Transformed Chebyshev Grid Points. SIAM J. Sci. Comput. 2006, 28, 1798-1811. [CrossRef]

50. Al-Juaydi, H.S. On Approximate Solutions of Singular Perturbation Boundary Value Problems. Master's Thesis, PSAU University, Al-Kharj, Saudi Arabia, 2021. (Unpublished). 